\title{
Effects of protonation on the hydrolysis of triphosphate in vacuum and the implications for catalysis by nucleotide hydrolyzing enzymes
}

Farooq Ahmad Kiani ${ }^{2}$ and Stefan Fischer ${ }^{1^{*}}$

\begin{abstract}
Background: Nucleoside triphosphate (NTP) hydrolysis is a key reaction in biology. It involves breaking two very stable bonds (one $\mathrm{P}-\mathrm{O}$ bond and one $\mathrm{O}-\mathrm{H}$ bond of water), in either a concurrent or a sequential way. Here, we systematically examine how protonation of the triphosphate affects the mechanism of hydrolysis.

Results: The hydrolysis reaction of methyl triphosphate in vacuum is computed with protons in various numbers and position on the three phosphate groups. Protonation is seen to have a strong catalytic effect, with the reaction mechanism depending highly on the protonation pattern.

Conclusion: This dependence is apparently complicated, but is shown to obey a well-defined set of rules: Protonation of the $a$ - and $\beta$-phosphate groups favors a sequential hydrolysis mechanism, whereas $\gamma$-protonation favors a concurrent mechanism, the two effects competing with each other in cases of simultaneous protonation. The rate-limiting step is always the breakup of the water molecule while it attacks the $\gamma$-phosphorus, and its barrier is lowered by $\gamma$-protonation. This step has significantly lower barriers in the sequential reactions, because the dissociated $\gamma$-metaphosphate intermediate $\left(\mathrm{P}_{\gamma} \mathrm{O}_{3}^{-}\right)$is a much better target for water attack than the un-dissociated $\gamma$-phosphate $\left(-\mathrm{P}_{\gamma} \mathrm{O}_{4}^{2-}\right)$. The simple chemical logic behind these rules helps to better understand the catalytic strategy used by NTPase enzymes, as illustrated here for the catalytic pocket of myosin.

A set of rules was determined that describes how protonating the phosphate groups affects the hydrolysis mechanism of methyl triphosphate: Protonation of the $a$ - and/or $\beta$ - phosphate groups promotes a sequential mechanism in which $\mathrm{P}-\mathrm{O}$ bond breaking precedes the breakup of the attacking water, whereas protonation of the $\gamma$-phosphate promotes a concurrent mechanism and lowers the rate-limiting barrier of water breakup. The role played by individual protein residues in the catalytic pocket of triphosphate hydrolysing enzymes can be assigned accordingly.
\end{abstract}

Keywords: ATP hydrolysis, ATPase, GTPase, Enzymatic mechanism, Concurrent and sequential mechanisms, Computational biochemistry

\footnotetext{
* Correspondence: Stefan.Fischer@iwr.uni-heidelberg.de

${ }^{1}$ Computational Biochemistry, Interdisciplinary Center for Scientific

Computing (IWR), Heidelberg University, Im Neuenheimer Feld 205, D-69120

Heidelberg, Germany

Full list of author information is available at the end of the article
} 


\section{Background}

Nucleoside triphosphate (NTP) hydrolysis $[1,2]$ is an important enzymatic reaction in biology [3]. During this reaction, the triphosphate moiety is hydrolyzed into diphosphate and inorganic phosphate. The reaction requires the breaking of two stable bonds: the $\mathrm{P}_{\gamma}-\mathrm{O}_{\beta \gamma}$ bond of the triphosphate and one $\mathrm{O}-\mathrm{H}$ bond of the attacking water molecule $\left(W_{a}\right.$ in Fig. 1). This makes NTPs highly stable in water [4]. For example for ATP in presence of magnesium at $70{ }^{\circ} \mathrm{C}$ and $\mathrm{pH} \sim 7$, the hydrolysis reaction rate constant has been measured at a slow $4 \cdot 10^{-4} \mathrm{~min}^{-1}$, which corresponds to a high free energy barrier of $\sim 28 \mathrm{kcal} \mathrm{mol}^{-1}$ [5]. Two types of mechanisms have been proposed for the hydrolysis of triphosphate: [6, 7] 1) A concurrent mechanism, in which $\mathrm{P}_{\gamma}-\mathrm{O}_{\beta \gamma}$ cleavage and $\mathrm{O}-\mathrm{H}$ bond breaking are concerted (Fig. 1). 2) A sequential mechanism, in which the $\mathrm{P}_{\gamma}-\mathrm{O}_{\beta \gamma}$ bond breaks (Fig. 2c) before the $\mathrm{OH}^{-}$nucleophilic attack (Fig. 2d) [8, 9]. In vacuum, both mechanisms have similar high-energy barriers, respectively 44.0 and $45.9 \mathrm{kcal}$ $\mathrm{mol}^{-1}$ for concurrent and sequential reactions. NTPase enzymes accelerate the hydrolysis reaction by a factor of $10^{7}$ [10]. To help understand the catalytic mechanism in NTPase enzymes, we are studying here the triphosphate substrate in vacuum, and investigate in particular how protonation of different phosphate groups affects the hydrolysis reaction.

In the catalytic pocket of NTPase enzymes, many partial positive charges surround the triphosphate moiety of NTP. Figure 2a shows, for example, the active site of myosin with ATP bound in the catalytically competent conformation. The many hydrogen bonds donated by the NH moieties of the P-loop (for "phosphate-binding" loop) to the triphosphate moiety are seen in all NTPase binding sites. The positive electrostatic environment is further enhanced by Lys185 and H-bond donor Asn233 (Fig. 2a). These lysine, [11-13] and aspargine [14] (replaced by an arginine in some NTPases) [12, 15-17] residues are critical for the catalytic function of NTPases, as evidenced from kinetic and mutagenesis studies. To differentiate how interactions between this electrostatically positive environment and the three individual phosphate groups affects the hydrolytic mechanism and its energy barrier, we are studying here the effect of placing protons on triphosphate in vacuum, varying the number of such protons and their oxygen location on the triphosphate. This reveals that the location of the protons has a strong influence on the catalytic mechanism. We derive a simple set of chemical rules, which explain this effect and can be related to the catalytic strategy used by NTPases.

Triphosphate tends to chelate $\mathrm{Mg}^{2+}$ in solution, and in the enzymes, NTPs are always found with one $\mathrm{Mg}^{2+}$ complexed between the $\beta$ - and $\gamma$-phosphates. Therefore, it is important to study the triphosphate bound to $\mathrm{Mg}^{2+}$, [18] which should be fully coordinated. The $\mathrm{pK}_{\mathrm{a}}$ value of the reaction $\left[\mathrm{HATP}^{3-} \rightarrow \mathrm{ATP}^{4-}+\mathrm{H}^{+}\right]$is 6.95 at $25 \mathrm{C}^{\mathrm{O}}$ in the absence of magnesium [19]. The presence of magnesium makes this $\mathrm{pK}_{\mathrm{a}}$ drop by about 2 units (for example to 5.36 at $70 \mathrm{C}^{\circ}$ ) [5]. This means that the Mg/ATP complex is fully deprotonated in water, and therefore easily binds as $\mathrm{Mg}^{2+} / \mathrm{ATP}^{4-}$ to the enzymes. In the present study, only the triphosphate moiety of NTP is considered, using methyl triphosphate as a substrate analogue (Fig. 1, left panel). Five water molecules are present: one attacking (lytic) water $\mathrm{W}_{\mathrm{a}}$ placed apically relative to the $\gamma$-phosphate, and four water molecules complete the coordination shell of the $\mathrm{Mg}^{2+}$. It can be seen in Fig. $2 \mathrm{~b}$ that the energy-optimized conformation of this complex in vacuum is very similar to the conformation of the corresponding moiety of NTP in the enzymes (compare with Fig. 2a). Protonation states with up to three protons on the triphosphate were considered: A single proton was placed on either triphosphate oxygen $\alpha, \beta$ or $\gamma$ (see Fig. 1a for atomic nomenclature). In the doubly protonated triphosphate, two protons were placed on either the $\alpha \beta-, \alpha \gamma^{-}$, or $\beta \gamma^{-o x y g e n s . ~ I n ~ t h e ~ t r i p l y ~ p r o t o n a t e d ~ c a s e, ~}$ the three protons are on oxygens $\alpha, \beta$ and $\gamma$ (named here " $\alpha \beta \gamma$ " protonation). Together with the un-protonated (zero protons) case, a total of eight protonation states were investigated here. For each of these protonation states, it was attempted to obtain both a concurrent and a sequential reaction. Using the AM1/d quantum method, (with parameters optimized for the treatment of phosphates chelating magnesium, see Methods), [20] minimum energy paths (MEPs) were computed for each

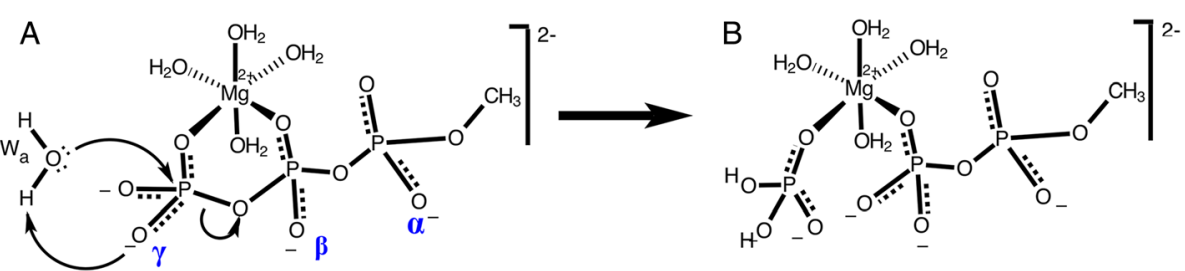

Fig. 1 Triphosphate hydrolysis. a Unprotonated methyl triphosphate reactant. The three protonation sites $(\alpha, \beta, \gamma)$ are labeled. The arrows show the electronic rearrangements of the concurrent reaction mechanism: concerted breaking of the $P_{\gamma}-O_{\beta \gamma}$ bond and lysis of water $W_{a}$. $\mathbf{b}$ Product state. The magnesium $\mathrm{Mg}^{2+}$ is hexa-coordinated by two oxygen atoms of the triphosphate and four water molecules 

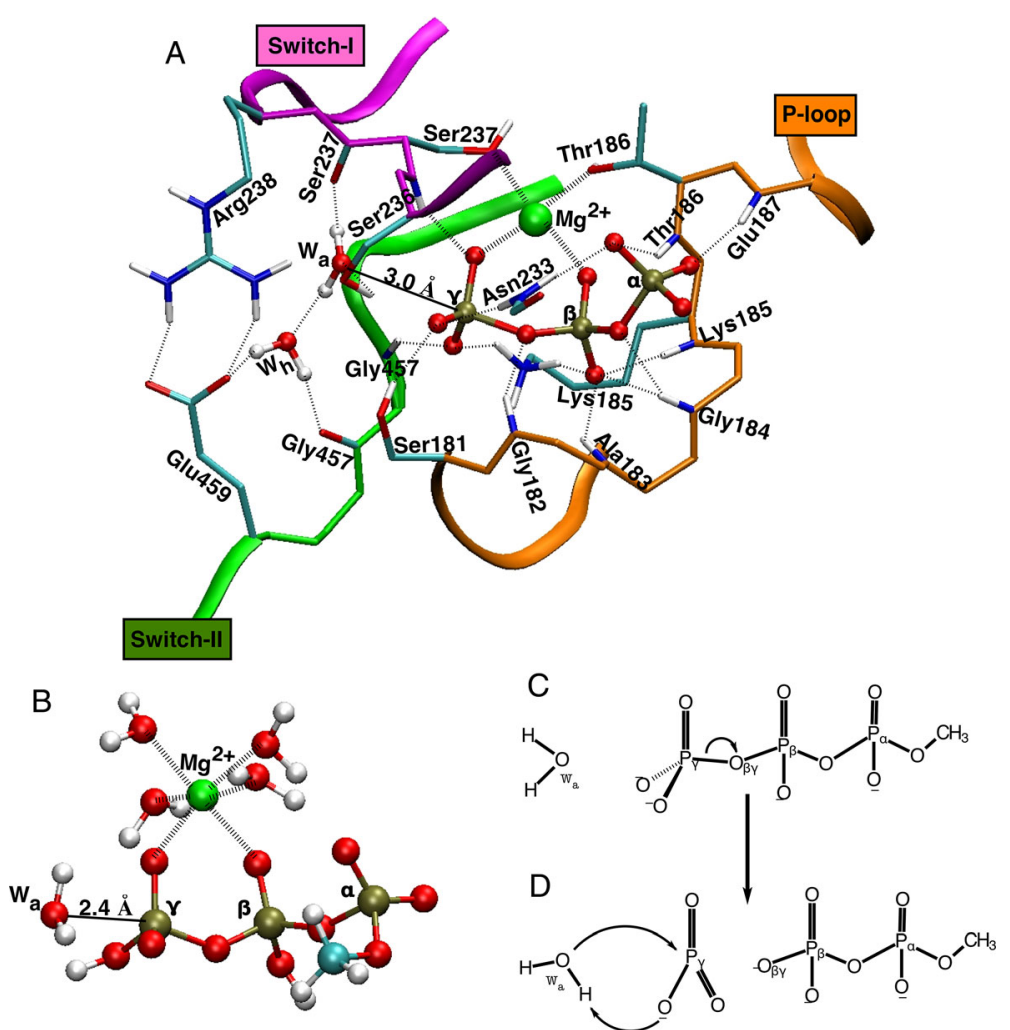

Fig. 2 Reactant state structure of triphosphate. a ATP bound to myosin (based on the 1VOM crystal structure). Only the triphosphate moiety (labeled $\mathrm{a}, \beta, \gamma$ ) of ATP is depicted. Two water molecules that coordinate $\mathrm{Mg}^{2+}$ are not shown. Thin dotted lines show hydrogen bonds shorter than $2.8 \AA$ between the heavy atoms. b Methyl triphosphate ( $\beta$ - and $\gamma$-protonated), after energy minimization in vacuum. The $\mathrm{Mg}^{2+}$ hexa-coordination is depicted with dotted lines. $\mathbf{c}$ First step of the sequential mechanism: breaking of the $\mathrm{P}_{\gamma}-\mathrm{O}_{\beta \gamma}$ bond to form a stable $\mathrm{P}_{\gamma} \mathrm{O}_{3}^{-}$metaphosphate. $\mathbf{d}$ Second step of the sequential mechanism: lysis of water $W_{a}$ and simultaneous attack of the metaphosphate

reaction. The MEPs give a complete description of the process, in terms of both mechanism and rate limiting energy barrier, and yield a molecular movie of each hydrolysis reaction (available in Additional file 1).

Our results show that the mechanism of hydrolysis is very dependent on the location of the protons on the triphosphate: Protonation of the $\alpha$ - and $\beta$-phosphate groups favors the sequential mechanism, whereas protonation on the $\gamma$-phosphate favors a concurrent reaction. This can be explained in terms of the charge shifts that occur during these different reaction mechanisms. Overall, the lowest barriers are achieved with the sequential mechanism, which can be explained by the fact that the dissociated $\mathrm{P}_{\gamma} \mathrm{O}_{3}^{-}$metaphosphate intermediate (Fig. 2d) is a better target for the subsequent attack by the lytic water $\mathrm{W}_{\mathrm{a}}$ than the $-\mathrm{P}_{\gamma} \mathrm{O}_{4}^{2-}$ group in the concurrent reaction (Fig. 1). This is consistent with the catalytic mechanism in NTPases, which has been shown to proceed via a sequential reaction [7, 21-26]. The present results help to explain why the many $\mathrm{H}$-bonds made by the P-loop to the $\alpha$ and $\beta$-phosphates of the NTP favor such a sequential mechanism in NTPases.

\section{Results}

\section{Reaction paths}

To obtain one concurrent and one sequential reaction path for each of the eight protonation states mentioned above, initial constraints on the atomic coordinates were applied to channel the refinement of the minimum energy paths (MEP) into a corresponding valley of the potential energy surface. However, after all constraints are removed, it turns out that there are not 16 such MEPs. Only 12 MEPs could be found on the respective potential energy landscapes: 5 concurrent MEP (whose energy barriers are listed in Table 1) and 7 sequential MEPs

Table 1 Effect of protonation on the barrier $\Delta E \neq$ of the concurrent reaction ${ }^{[a]}$

\begin{tabular}{lllllll}
\hline$n_{p}=0$ & $n_{p}=1$ & & $n_{p}=2$ & & $n_{p}=3$ & \\
\hline 44.0 & $\alpha:$ & {$[b]$} & $a \gamma:$ & 34.5 & $a \beta \gamma:$ & 39.9 \\
& $\beta:$ & {$[b]$} & a $\beta:$ & {$[b]$} & & \\
& $\gamma:$ & 32.4 & $\beta \gamma:$ & 35.1 & & \\
\hline
\end{tabular}

${ }^{[a]} \Delta \mathrm{E}^{\ddagger}$ is the energy $\left(\mathrm{AM} 1 / \mathrm{d}\right.$ in $\mathrm{kcal} \mathrm{mol}^{-1}$ ) difference between the optimized reactant and the rate limiting transition state (saddle point). $n_{p}$ is the number of protons on the triphosphate ( $a, \beta$ and $\gamma$ indicate which phosphate group is protonated). ${ }^{[b]}$ Various searches for a concurrent reaction failed (hydrolysis always proceeded through a sequential mechanism, see Table 2) 
(listed in Table 2). For the concurrent reaction, there is no MEP on the energy landscape for protonation states $\alpha, \beta$, and $\alpha \beta$, while for the sequential reaction, no MEP could be found for single protonation on $\gamma$. The explanation for this is given below. The energy profiles along the 12 MEPs are shown in Fig. 3. In the following sections, the characteristics of these paths are presented, starting with the concurrent paths and continuing with the sequential paths. Twelve molecular movies showing the conformational changes that occur during these MEPs are available as Supplemental Information.

\section{Concurrent paths}

\section{Unprotonated case $\left(n_{p}=0\right)$}

The energy profile of the concurrent MEP obtained in absence of any protons on the triphosphate is plotted in Fig. 3a. It has a rate-limiting barrier of $44 \mathrm{kcal} \mathrm{mol}^{-1}$ about half-way ( $\lambda=48 \%$, see legend of Fig. 3 for a definition of $\lambda$ ) along the MEP. The structure of that transition state is shown in Fig. 4a. The $\gamma$-phosphorus has a distance to the leaving oxygen $\mathrm{O}_{\beta \gamma}$ (see Fig. 2c for atomic nomenclature) of $1.71 \AA$ and a distance to the oxygen of the attacking water $\mathrm{W}_{\mathrm{a}}$ equaling $2.01 \AA$. These two short distances reflect the fact that the breaking of the $\mathrm{P}_{\gamma}-\mathrm{O}_{\beta \gamma}$ bond is concerted with the formation of the $\mathrm{O}_{\mathrm{a}}-\mathrm{P}_{\gamma}$ bond characteristic for a concurrent mechanism. In molecular movie $\mathrm{C} 1$ (Additional file 2), it can be seen that shortly before the transition state is reached, one of the two protons of water $\mathrm{W}_{\mathrm{a}}$ is transferred onto one of the oxygens of the $\gamma$-phosphate, which acts here as a "catalytic base". The high-energy barrier is due to the fact that two strong bonds are being broken nearly

Table 2 Effect of protonation on the barriers of the sequential reaction ${ }^{[a]}$

\begin{tabular}{llllll}
\hline $\mathrm{n}_{p}{ }^{[\mathrm{b}]}$ & & $\Delta E_{1}{ }^{\ddagger[c]}$ & $E_{\text {meta [d] }}$ & $E_{2[\mathrm{e}]}$ & $\Delta E_{2}{ }^{\ddagger[\mathrm{f}]}$ \\
\hline 0 & & 14.2 & 11.2 & 45.9 & 34.7 \\
1 & $\mathrm{a}:$ & 1.82 & -7.07 & 30.4 & 37.5 \\
1 & $\beta:$ & 1.99 & -36.0 & -4.6 & 31.4 \\
1 & $\gamma:{ }^{[\mathrm{g}]}$ & - & - & - & - \\
2 & $\mathrm{a} \beta:$ & 0.34 & -38.2 & -9.0 & 29.2 \\
2 & $\mathrm{a}::$ & 14.5 & 13.9 & 40.9 & 27.0 \\
2 & $\beta \gamma:$ & 8.02 & 3.8 & 29.1 & 25.3 \\
3 & $\mathrm{a} \beta \gamma:$ & 4.9 & -3.27 & 18.6 & 21.9 \\
\hline
\end{tabular}

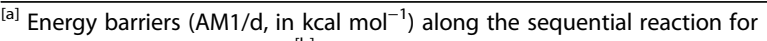
different protonation states. ${ }^{[b]} \mathrm{n}_{\mathrm{p}}$ is the number of protons on the triphosphate (a, $\beta$ and $\gamma$ indicate which phosphate is protonated). ${ }^{[c]} \Delta E_{1}^{\neq}$is the barrier of the metaphosphate formation, i.e., the energy difference between the saddle point for $\mathrm{P}_{\gamma}-\mathrm{O}_{\beta \gamma}$ bond cleavage and the reactant. Note that $\Delta E_{1}^{\neq}$is the same as $E_{1}$ defined in the main text. ${ }^{[\mathrm{d}]} E_{\text {meta }}$ is the energy of the geometryoptimised metaphosphate intermediate, relative to the initial reactant. ${ }^{\left[{ }^{[e]}\right.} E_{2}$ is the energy of the saddle point for $W_{a}$ attack onto the metaphosphate, relative to the reactant. ${ }^{[\mathrm{ff}} \Delta E_{2}^{+}=\left(E_{2}-E_{\text {meta }}\right)$ is the activation barrier for water $\mathrm{W}_{\mathrm{a}}$ attack onto the metaphosphate. ${ }^{[\mathrm{g}]}$ Various searches for a sequential reaction failed (hydrolysis always proceeded through a concurrent mechanism) simultaneously (Fig. 1): the $\mathrm{P}_{\gamma}-\mathrm{O}_{\beta \gamma}$ bond and the $\mathrm{O}_{\mathrm{a}}-\mathrm{H}$ bond of water $\mathrm{W}_{\mathrm{a}}$. Moreover, the $\gamma$-phosphate group $\left(-\mathrm{OP}_{\gamma} \mathrm{O}_{3}^{2-}\right)$ formally bears two negative charges, which makes it a poor target for the nucleophilic attack by the $\mathrm{O}_{\mathrm{a}}-\mathrm{H}^{-}$moiety of water $\mathrm{W}_{\mathrm{a}}$. Also, the tetrahedral geometry of the $-\mathrm{OP}_{\gamma} \mathrm{O}_{3}^{2-}$ group does not allow for a close approach of the phosphorus by water $\mathrm{W}_{\mathrm{a}}$.

\section{Single protonation $\left(n_{P}=1\right)$}

The energy profile of the concurrent MEP obtained with one proton placed on the $\gamma$-phosphate is plotted in Fig. 3b. The rate limiting energy barrier is $32.4 \mathrm{kcal} \mathrm{mol}^{-1}$ (located $27 \%$ along the MEP) and its structure is shown in Fig. 4b. In spite of the fact that this structure and the reaction (see Additional file 3: Movie C2) are very similar to the unprotonated concurrent case (compare Fig. $4 \mathrm{a}$ and $\mathrm{b}$ ), adding a proton on the $\gamma$-phosphate significantly lowers (by $11.6 \mathrm{kcal} \mathrm{mol}^{-1}$, Table 1) the activation barrier of concurrent hydrolysis. This can be explained by the fact that the protonated $\gamma$-phosphate $\left(-\mathrm{OP}_{\gamma} \mathrm{O}_{3} \mathrm{H}^{-}\right)$bears one less negative charge than the un-protonated $-\mathrm{OP}_{\gamma} \mathrm{O}_{3}^{2-}$, so that its repulsion with the partial negative charge on oxygen $\mathrm{O}_{a}$ of water $\mathrm{W}_{\mathrm{a}}$ is diminished. In the cases of single protonation on either the $\alpha$ - or $\beta$-phosphates, it was not possible to isolate concurrent MEPs. In spite of using initial constraints, the MEPs always reverted to a sequential reaction (presented below).

\section{Double protonation $\left(n_{P}=2\right)$}

The energy profiles of the concurrent reaction obtained with two protons placed on the $\alpha \gamma$ - or $\beta \gamma$-phosphates are plotted in Fig. 3c. Structurally, these reactions proceed (Additional file 4: Movie C3 and Additional file 5: Movie C4) very similarly to the un-protonated and the $\gamma$-protonated concurrent cases. Their transition state structures (Fig. 4c and d, respectively) are very similar to the other concurrent transition states (Fig. 4). Their energy barriers $\left(34.5 \mathrm{kcal} \mathrm{mol}^{-1}\right.$ for $\alpha \gamma$ and $35.1 \mathrm{kcal} \mathrm{mol}^{-1}$ for $\beta \gamma)$ are slightly higher $\left(2-3 \mathrm{kcal} \mathrm{mol}^{-1}\right.$, Table 1$)$ than the barrier of the singly protonated case. This may be explained by the fact that $\alpha$ - or $\beta$-protonation favors a dissociation of the $\gamma$-phosphate (as will be shown below), which involves larger $\mathrm{P}_{\gamma}-\mathrm{O}_{\beta \gamma}$ distances than those of the concurrent transition state for single $\gamma$-protonation. Indeed, the $\mathrm{P}_{\gamma}-\mathrm{O}_{\beta \gamma}$ distance is $1.58 \AA$ and $1.60 \AA$ for the $\alpha \gamma$ and $\beta \gamma$ protonation, respectively, slightly larger than the $1.57 \AA$ for single $\gamma$-protonation (Fig. 4). Thus, adding $\alpha$ - or $\beta$-protons on the concurrent transition states raises the barrier relative to the singly $\gamma$-protonated triphosphate. For the same reason, double protonation on the $\alpha \beta$ phosphates always resulted in a sequential MEP, in spite of attempts to use initial constraints towards a concurrent reaction. 
A

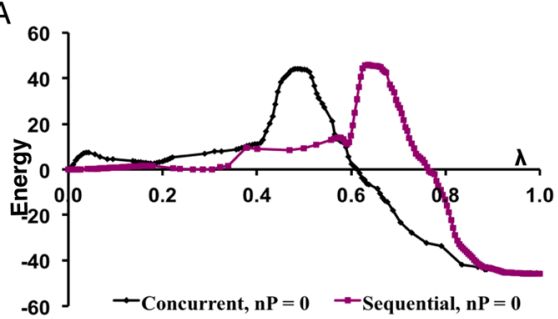

C

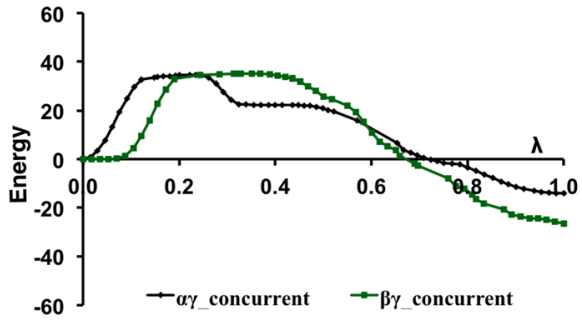

$\mathrm{E}$

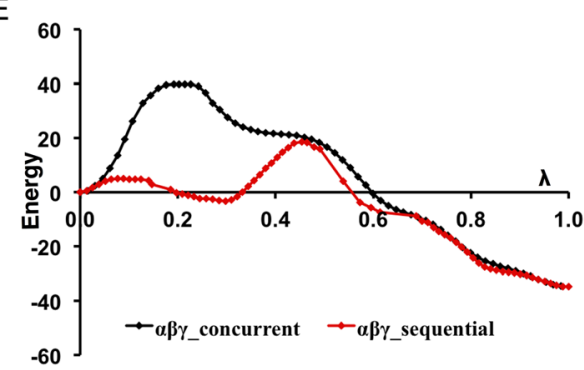

B

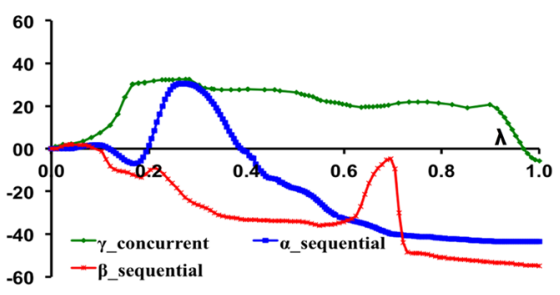

D

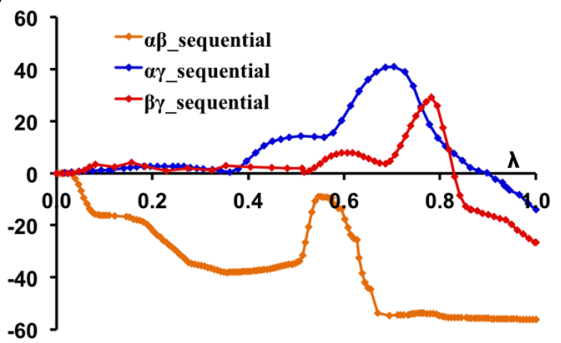

Fig. 3 Energy profiles (in $\mathrm{kcal} \mathrm{mol}^{-1}$ ) for methyl triphosphate hydrolysis in different protonation states. a No protons on the triphosphate $\left(\mathrm{n}_{\mathrm{p}}=0\right)$. b Single protonation $\left(n_{p}=1\right)$. Double protonation $\left(n_{p}=2\right)$ resulting in $\mathbf{c}$ concurrent reactions or $\mathbf{d}$ sequential reactions. e triple protonation $\left(n_{p}=3\right)$. Greek letters $(a, \beta, \gamma)$ indicate on which phosphate group the proton is located (see Fig. 1 for nomenclature). The energy barriers seen here correspond to those listed in Tables 1 and 2 . The energy is plotted as a function of the curvilinear reaction coordinate $(\lambda)$, which measure the progress of the reaction as the sum of conformational changes that occur along the MEP (in terms of RMS-change in all atomic coordinates), starting from the reactant state $(\lambda=0)$. Here $\lambda$ is normalized by the total length of the curvilinear MEP, so that the hydrolysis product has $\lambda=1$
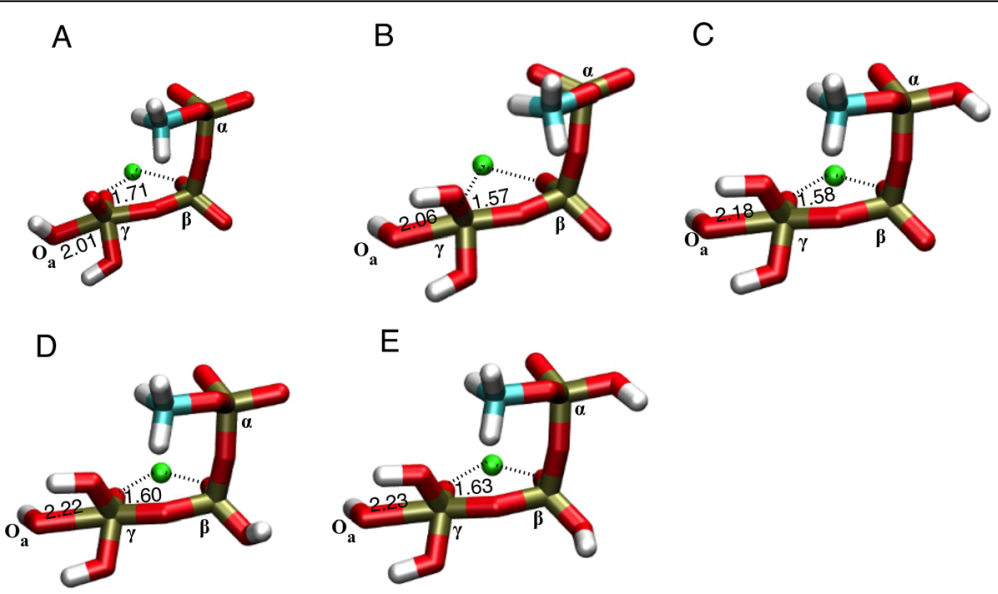

E

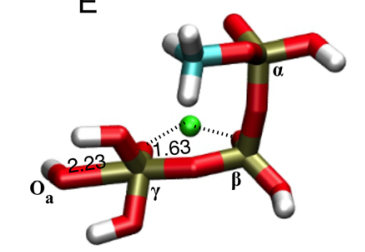

Fig. 4 Transition state in the concurrent reactions. a Methyl triphosphate fully deprotonated (number of protons $\left.n_{p}=0\right)$, $\mathbf{b} \gamma$-protonated $\left(n_{p}=1\right)$, c ay-protonated $\left(n_{p}=2\right)$, d $\beta \gamma$-protonated $\left(n_{p}=2\right)$ and e $a \beta \gamma$-protonated $\left(n_{p}=3\right)$. See also caption of Fig. 3. Coordination bonds to Mg ${ }^{2+}$ are shown as dotted line. The four water molecules coordinating the $\mathrm{Mg}^{2+}$ are not shown, but are present in the calculations. The distance from the $P_{\gamma}$ to the leaving and attacking oxygen atoms is indicated in $\AA$ 
Triple protonation $\left(n_{P}=3\right)$

The energy profile of the concurrent MEP with triply $(\alpha, \beta, \gamma)$ protonated triphosphate is plotted in Fig. 3e. The transition state (Fig. 4e) has an even larger $\mathrm{P}_{\gamma}-\mathrm{O}_{\beta \gamma}$ distance $(1.63 \AA)$ than the $\alpha \gamma$ or $\beta \gamma$ doubly protonated transition states (Fig. 4c and d). The unfavorable effect of the $\alpha$ and $\beta$ protons on the concurrent energy barrier (described above) is more than cumulative, since it is $7.5 \mathrm{kcal} \mathrm{mol}^{-1}$ higher than for single $\gamma$-protonation (Table 1). Additional file 6: Movie C5 shows the structural changes during this reaction.

\section{Sequential paths}

All concurrent MEPs described above have one high rate-limiting transition state (shown in Fig. 4), which belongs to the simultaneous breaking of the $\mathrm{P}_{\gamma}-\mathrm{O}_{\beta \gamma}$ bond and attack of water $\mathrm{W}_{\mathrm{a}}$ (Fig. 1). In contrast, sequential MEPs have two distinct transition states: The first one belongs to the breaking of the $\mathrm{P}_{\gamma}-\mathrm{O}_{\beta \gamma}$ bond to form a planar metaphosphate (for example, $\mathrm{P}_{\gamma} \mathrm{O}_{3}^{-}$for $\mathrm{n}_{\mathrm{P}}=0$ ) intermediate (Fig. 2c), followed by the second transition state which pertains to the breaking of water $\mathrm{W}_{\mathrm{a}}$ (Fig. $2 \mathrm{~d}$ ) and attack onto the $\mathrm{P}_{\gamma} \mathrm{O}_{3}^{-}$molecule (for example, to form the $\mathrm{H}_{2} \mathrm{P}_{\gamma} \mathrm{O}_{4}^{-}$for $\mathrm{n}_{\mathrm{P}}=0$ ). The two corresponding saddle points were geometry-optimized for each sequential MEP. Their energies (relative to the reactant state) are called here $E_{1}$ and $E_{2}$, respectively for the first and second transition state (listed in Table 2). For the first transition state, the distances of the $\gamma$-phosphorus to the leaving and attacking oxygens are listed in Table 3. The structure of the 2nd transition state of each sequential MEP is shown in Fig. 5. The metaphosphate intermediate state was also geometry optimized and its energy is called here $E_{\text {meta }}$ (so that the barrier of the second step is $\left.\Delta E_{2}=E_{2}-E_{\text {meta }}\right)$.

Table 3 Inter-atomic distances $[\AA]$ in the saddle point of metaphosphate formation ${ }^{[a]}$

\begin{tabular}{llll}
\hline$n_{p}{ }^{[b]}$ & $P_{\gamma}-O_{\beta \gamma}{ }^{[c]}$ & $\left.P_{\gamma}-O_{a}{ }^{[d]}\right]$ \\
\hline 0 & $a$ & 2.32 & 2.83 \\
1 & $\beta$ & 1.92 & 2.47 \\
1 & $a \beta$ & 1.72 & 2.51 \\
2 & $\beta \gamma$ & 1.85 & 2.45 \\
2 & $a \gamma$ & 2.02 & 2.34 \\
2 & a & 2.12 & 2.33 \\
3 & a $3 \gamma$ & 1.98 & 2.40 \\
\hline
\end{tabular}

${ }^{[a]}$ Structures corresponding to the energy $\Delta E_{1}^{+}$in Table $2 .{ }^{[b]} \mathrm{n}_{\mathrm{p}}$ is the number of protons on the triphosphate $(\alpha, \beta$ and $\gamma$ indicate which phosphate is protonated. ${ }^{[c]}$ Distance between $P_{\gamma}$ and the leaving oxygen $O_{\beta \gamma}$ (see Fig. 1d for atomic nomenclature). ${ }^{[d]}$ Distance between $P_{Y}$ and the attacking oxygen of water $\mathrm{W}_{\mathrm{a}}$

\section{Unprotonated case $\left(n_{P}=0\right)$}

The energy profile of the sequential MEP obtained without protons on the triphosphate is plotted in Fig. 3a. Barrier $\Delta E_{1}$ is $14.1 \mathrm{kcal} \mathrm{mol}^{-1}$ at $\lambda=57 \%$. The energy of the metaphosphate intermediate is $E_{\text {meta }}=11.2 \mathrm{kcal}$ $\mathrm{mol}^{-1}$, so that the second barrier (at $\lambda=64 \%$ ) is $\Delta E_{2}=$ $45.9-11.2=34.7 \mathrm{kcal} \mathrm{mol}^{-1}$ (Table 2). Thus, step 1 (the breaking of the $\mathrm{P}_{\gamma}-\mathrm{O}_{\beta \gamma}$ bond) has a much lower barrier than step 2 (water attack). This turns out to be the case for all other sequential MEPs (see Table 2). The transition state for step 2 is shown in Fig. $5 \mathrm{a}$, in which the planar $\mathrm{P}_{\gamma} \mathrm{O}_{3}^{-}$molecule is clearly recognizable and the $\mathrm{O}_{\mathrm{a}}-\mathrm{P}_{\gamma}$ distance is short at $2.3 \AA$. The sequentiality of step 1 and step 2 can be seen in Additional file 7: Movie S1. Relative to the reactant, the energy $\left(E_{2}=45.9 \mathrm{kcal} \mathrm{mol}^{-1}\right)$ of the rate-limiting transition state is similar to that of the un-protonated concurrent reaction $(\Delta E=44.0 \mathrm{kcal} \mathrm{mol}$ ${ }^{-1}$, Table 1). Thus, in absence of protons, there is no clear preference for either the concurrent or the sequential mechanism of hydrolysis.

\section{Single protonation $\left(n_{P}=1\right)$}

The energy profiles of the sequential MEP obtained with one proton placed on either the $\alpha$ - or the $\beta$-phosphate are plotted in Fig. 3b. In both cases, the effect of these protonations on the barrier of the first step $\left(\mathrm{P}_{\gamma}-\mathrm{O}_{\beta \gamma}\right.$ bond breaking) is very strong, lowering $\Delta E_{1}$ by $\sim 12 \mathrm{kcal}$ $\mathrm{mol}^{-1}$ relative to the un-protonated case: $\Delta E_{1}=1.82 \mathrm{kcal}$ $\mathrm{mol}^{-1}$ (at $\lambda=9 \%$ ) for $\alpha$ - and $\Delta E_{1}=1.99 \mathrm{kcal} \mathrm{mol}^{-1}$ (at $\lambda=4 \%$ ) for $\beta$-protonation (Table 2). Such low barriers mean that the dissociation of the $\mathrm{P}_{\gamma}-\mathrm{O}_{\beta \gamma}$ bond is nearly unhindered at room temperature when the triphosphate is protonated on the $\alpha$ - or $\beta$-positions, a remarkable result. Moreover, the resulting metaphosphate intermediates are more stable than the reactant state $\left(E_{\text {meta }}<0\right.$, Table 2).

How can protonation of the $\alpha \beta$-diphosphate moiety promote metaphosphate dissociation in such a dramatic way? The answer lies in the change of charge distribution upon dissociation: For example, in the unprotonated triphosphate reactant, two formal negative charges are located on the $\gamma$-phosphate $\left(-\mathrm{OP}_{\gamma} \mathrm{O}_{3}^{2-}\right)$ and two negative charges are on the $\alpha \beta$-diphosphate moiety (Fig. 2c). In the metaphosphate intermediate, the $\mathrm{P}_{\gamma} \mathrm{O}_{3}^{-}$ bears a single negative charge and the $\alpha \beta$-diphosphate has three negative charges (Fig. $2 \mathrm{~d}$ ). Thus, one negative charge shifts from the $\gamma$ - to the $\alpha \beta$-phosphates upon dissociation. This charge shift is strongly favored when a positive charge $\left(\mathrm{H}^{+}\right)$is placed onto the $\alpha \beta$-moiety.

The barrier of step 2 (breaking of water $\mathrm{W}_{\mathrm{a}}$ ) is $\Delta E_{2}=$ $37.5 \mathrm{kcal} \mathrm{mol}^{-1}$ for $\alpha$ - and $\Delta E_{2}=31.4 \mathrm{kcal} \mathrm{mol}^{-1}$ for $\beta$ protonation (Table 2), which is similar to that of the unprotonated case $\left(\Delta E_{2}=34.7 \mathrm{kcal} \mathrm{mol}^{-1}\right)$. This indicates that the effect of these protonations on step 2 is limited, 


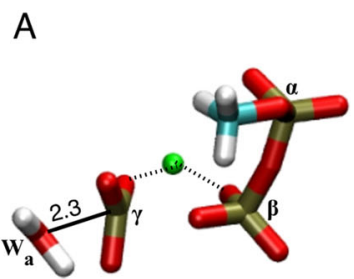

$\mathrm{D}$

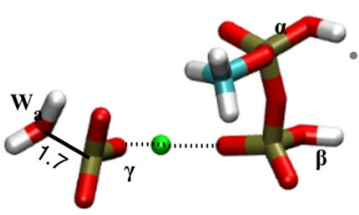

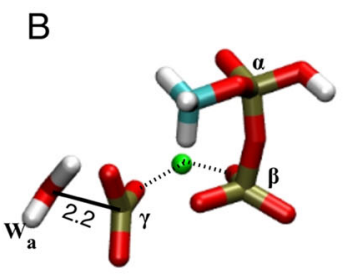

E

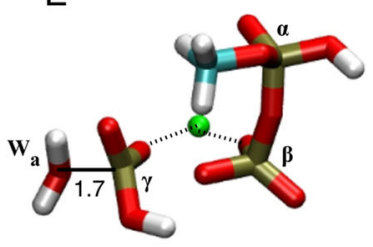

C

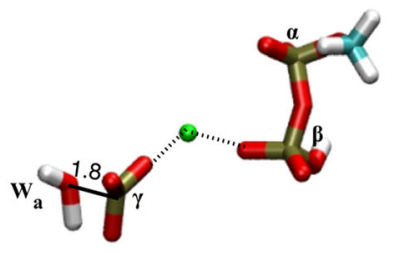

$\mathrm{F}$

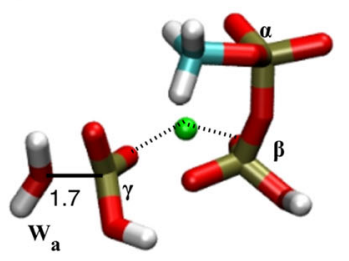

G

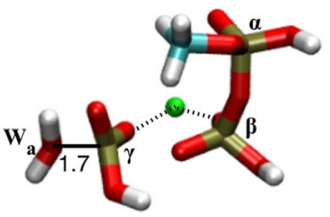

Fig. 5 Transition state of the second step ( $W_{a}$ attack onto $\gamma$-metaphosphate) in sequential reactions. a Methyl triphosphate fully de-protonated (number of protons $\left.n_{p}=0\right), \mathbf{b}$ a-protonated $\left(n_{p}=1\right), \mathbf{c} \beta$-protonated $\left(n_{p}=1\right), \mathbf{d}$ a $\beta$-protonated $\left(n_{p}=2\right)$, e ay-protonated $\left(n_{p}=2\right), \mathbf{f} \beta \gamma$-protonated $\left(n_{p}=2\right)$ and $\mathbf{g}$ aß $\gamma$-protonated $\left(n_{p}=3\right)$. The distance between the oxygen atom of water $W_{a}$ and the $\gamma$-phosphorus (solid line) is given in $\AA$. The coordination bonds to the $\mathrm{Mg}^{2+}$ are shown as dotted line. The four water molecules coordinating the $\mathrm{Mg}^{2+}$ are not shown, but are present in the calculations

as would be expected from the fact that the $\alpha \beta$-moiety is no longer covalently bound to the $\gamma$-phosphate when the later gets attacked by water $\mathrm{W}_{\mathrm{a}}$ (see the corresponding transition states in Fig. 5b and c). Note that it is difficult to compare the energy of the metaphosphate intermediate $\left(E_{\text {meta }}\right)$ of the $\alpha$ - and $\beta$-cases, due to the large conformational change that occurs (from $\lambda=21$ to $58 \%$ ) after metaphosphate formation in the $\beta$-case (compare Additional file 8: Movie S2 and Additional file 9: Movie S3).

All attempts to obtain a sequential MEP with one proton placed on the $\gamma$-phosphate failed, because the reaction always became concurrent. This effect can be explained in terms of the above mentioned charge shift: Placing a positive charge $\left(\mathrm{H}^{+}\right)$on the $\gamma$-phosphate strongly disfavors the shift of the negative charge from the $\gamma$ - to the $\alpha \beta$-moiety (Fig. $2 c \rightarrow d$ ) that needs to take place upon metaphosphate dissociation. Therefore, placing a proton on the $\gamma$-phosphate destabilizes the metaphosphate so much, that the "transition state" of step 1 is no longer a saddle-point on the energy surface (consequently, a MEP can not be found).

\section{Double protonation $\left(n_{P}=2\right)$}

Placing two protons on the $\alpha \beta$-moiety (one on the $\alpha$-, the other on the $\beta$-phosphate) favors the shift of negative charge from the $\gamma$ - to $\alpha \beta$-phosphates even more than a single proton. Not surprisingly, the barrier of metaphosphate dissociation drops even lower in this case, $\Delta E_{1}=0.34 \mathrm{kcal}$ $\mathrm{mol}^{-1}$ (Table 2). The corresponding energy profile is plotted in Fig. 3d, where this barrier (located at $\lambda=2 \%$ ) can be seen to be so low that the first step is essentially barrierless. After some rearrangements of the metaphosphate intermediate (from $\lambda=2$ to $35 \%$, see also Additional file 10: Movie S4), the barrier of step 2 (breaking of water $\mathrm{W}_{\mathrm{a}}$ ) is $\Delta E_{2}=29.2 \mathrm{kcal} \mathrm{mol}^{-1}$ (transition state shown in Fig. $5 \mathrm{~d}$ ), which is similar to the value obtained for single protonation on $\beta\left(\Delta E_{2}=31.4 \mathrm{kcal} \mathrm{mol}^{-1}\right.$, Table 2$)$ and confirms that protonation of the $\alpha \beta$-moiety does not significantly affect step 2 of the sequential reactions.

Double protonation on the $\alpha \gamma$ - or $\beta \gamma$-phosphates has a very different effect than the double protonation of the $\alpha \beta$-moiety described above, as can be seen by comparing their three energy profiles (Fig. 3d). Indeed, the resulting barrier for step 1 is $\Delta E_{1}=14.5 \mathrm{kcal} \mathrm{mol}^{-1}$ for $\alpha \gamma$ protonation, as high as for step 1 in the un-protonated case $\left(\Delta E_{1}=14.2 \mathrm{kcal} \mathrm{mol}^{-1}\right.$ Table 2), and much higher than for the singly $\alpha$-protonated case $\left(\Delta E_{1}=1.82 \mathrm{kcal}\right.$ $\left.\mathrm{mol}^{-1}\right)$. Thus, protonation on the $\gamma$-phosphate counteracts the promoting effect of $\alpha$-protonation on the metaphosphate dissociation step. As described above, this is due to the unfavorable effect of the positive charge $\left(\mathrm{H}^{+}\right)$ 
on the $\gamma$-position, which opposes the charge shift from the $\gamma$ - to the $\alpha \beta$-moieties, thereby suppressing the favorable effect of $\alpha$-protonation. The same behavior happens for double protonation on $\beta \gamma$, for which $\Delta E_{1}=8.02 \mathrm{kcal} \mathrm{mol}^{-1}$ (Table 2). This is not as high as for $\alpha \gamma$-protonation, but still significantly higher than the single $\beta$-protonation $\left(\Delta E_{1}=\right.$ $2.0 \mathrm{kcal} \mathrm{mol}^{-1}$, Table 2). The fact that $\beta \gamma$ - has a smaller $\Delta E_{1}$ than $\alpha \gamma$-protonation shows that the promoting effect on dissociation is stronger for protonation on the $\beta$ phosphate than on the $\alpha$-phosphate. This is not surprising, since the formal charge change upon dissociation is larger on the $\beta$-phosphate $(1 \mathrm{e} \rightarrow 2 \mathrm{e})$ than on the $\alpha$ phosphate $(1 \mathrm{e} \rightarrow 1 \mathrm{e})$, as illustrated by the charge distributions of Fig. $2 \mathrm{c}$ and $\mathrm{d}$.

The $\Delta E_{2}$ barrier of step $2\left(\mathrm{~W}_{\mathrm{a}}\right.$ water attack) is lower for the $\alpha \gamma$ - and $\beta \gamma$-cases, 27.0 and $25.3 \mathrm{kcal} \mathrm{mol}^{-1}$ respectively (for structures shown in Fig. $5 \mathrm{e}$ and $\mathrm{f}$ ), than for single protonation on $\alpha$ or $\beta(37.5$ and $31.4 \mathrm{kcal} \mathrm{mol}$ ${ }^{-1}$ respectively, see Table 2 ). The reason for this is the same as the one given above to explain barrier lowering in the concurrent singly $\gamma$-protonated case: The presence of a $\gamma$-proton leads to a dissociated metaphosphate in the neutral $\mathrm{HP}_{\gamma} \mathrm{O}_{3}$ form (instead of the negatively charged $\mathrm{P}_{\gamma} \mathrm{O}_{3}^{-}$form). This generates less repulsive interactions with the partial negative charge on oxygen $\mathrm{O}_{a}$ of water $\mathrm{W}_{\mathrm{a}}$ when it attacks this neutral metaphosphate in step 2. Thus, just as seen in the concurrent reactions, having a proton on the $\gamma$-phosphate facilitates the activation of water $\mathrm{W}_{\mathrm{a}}$ when it attacks the $\gamma$-phosphorus. Additional file 11: Movie S5 and Additional file 12: Movie S6 show the sequential $\alpha \gamma$ - and $\beta \gamma$-reactions, respectively.

\section{Triple protonation $\left(n_{P}=3\right)$}

The energy profile of the sequential MEP with a triply $(\alpha, \beta, \gamma)$ protonated triphosphate is plotted in Fig. 3e. The first barrier $\Delta E_{1}=4.9 \mathrm{kcal} \mathrm{mol}^{-1}$ (Table 2) is the result of a compromise between the favorable (i.e. decreasing $\Delta E_{1}$ ) effect of having two protons on the $\alpha \beta$ moiety (which favors the charge shift in Fig. $2 \mathrm{c} \rightarrow \mathrm{d}$ ), and the unfavorable (i.e. raising $\Delta E_{1}$ ) effect of having a proton on the $\gamma$-phosphate (which disfavors the charge shift).

The transition state of step 2 (Fig. $5 \mathrm{~g}$ ) gives a barrier $\Delta E_{2}=21.9 \mathrm{kcal} \mathrm{mol}^{-1}$. This is the lowest of all $\Delta E_{2}$ values (Table 2), which can be related to the fact that an increase in the total number of protons (i.e., a decrease in the net negative charge) on the triphosphate leads to less repulsion with the $\mathrm{O}_{\mathrm{a}} \mathrm{H}^{-}$group that attacks the $\gamma$ phosphorus in step 2. Indeed, the values of $\Delta E_{2}$ gradually drop as one looks down the right column of Table 2. Overall, the triply protonated sequential MEP has the lowest rate limiting barrier of all paths examined here, and is shown in Additional file 13: Movie S7.

\section{Discussion}

\section{Principle effects of ( $\alpha, \beta$ or $\gamma)$-protonation}

The results obtained here for the different protonations of triphosphate can be explained by the four following principles:

1) $\alpha$ - and/or $\beta$-protonation favor the sequential reaction

When a single or two protons are placed on the $\alpha$ - and/or $\beta$-positions, hydrolysis is found to occur only via the sequential mechanism. Concurrent transition states can't be located for protonation cases $\alpha, \beta$ or $\alpha \beta$. The energy barrier for $\mathrm{P}_{\gamma}-\mathrm{O}_{\beta \gamma}$ bond breaking, $\Delta E_{1}$, is considerably lower for protonation cases $\alpha, \beta\left(\Delta E_{1} \sim 2 \mathrm{kcal} \mathrm{mol}^{-1}\right)$ and $\alpha \beta$ $\left(\Delta E_{1} \sim 0.34 \mathrm{kcal} \mathrm{mol}^{-1}\right)$ than for the dissociation barrier of the un-protonated case $\left(\Delta E_{1}=14.2 \mathrm{kcal}\right.$ $\mathrm{mol}^{-1}$ ), see Fig. 6a. All this shows that $\mathrm{P}_{\gamma}-\mathrm{O}_{\beta \gamma}$ bond dissociation is strongly favored when protons are added onto $\alpha$ or $\beta$ positions. This is because $\alpha$ - and/or $\beta$-protonation favors the negative charge shift from the $\gamma$-phosphate to the $\alpha, \beta$-diphosphate upon $\mathrm{P}_{\gamma}-\mathrm{O}_{\beta \gamma}$ bond breaking (Fig. $2 \mathrm{c} \rightarrow$ d): In un-protonated triphosphate, two formal negative charges reside on the $\alpha \beta$-diphosphate and two negative charges on the $\gamma$-phosphate. After $\mathrm{P}_{\gamma}-\mathrm{O}_{\beta \gamma}$ bond cleavage, the $\alpha \beta$-diphosphate moiety bears three negative charges and the $\gamma$-metaphosphate has one negative charge. The positive charge of a proton placed either on an $\alpha$ or a $\beta$ oxygen atom of triphosphate pulls the electron density away from the $\gamma$-phosphate group and towards the $\alpha \beta$-diphosphate moiety. This prepares for the electronic distribution of the dissociated metaphosphate state, thus explains the large reduction in the $\Delta E_{1}$ energy barrier. This stabilization effect is so strong that the resulting metaphosphate state constitutes a stable intermediate in the energy profile of all sequential reactions (see Fig. 3). The energy $E_{\text {meta }}$ of this intermediate is lower than the reactant $\left(E_{\text {meta }}<0\right)$ for all cases of protonation on exclusively $\alpha$ - and/or $\beta$-groups (Table 2). As is expected from the formal charge distribution of the dissociated state (Fig. 2d), this pulling effect on the electron-density towards the $\alpha \beta$-diphosphate is somewhat stronger for $\beta$-protonation than for $\alpha$-protonation (lower values of $E_{\text {meta }}$ for $\beta$-protonation in Table 2).

2) $\gamma$-protonation disfavors the sequential reaction The effect of $\gamma$-protonation is the opposite of the effect of $\alpha / \beta$-protonation and raises the $\Delta E_{1}$ energy barrier of $\mathrm{P}_{\gamma}-\mathrm{O}_{\beta \gamma}$ bond cleavage. When a $\gamma$-proton is added to an $\alpha$-protonated triphosphate, $\Delta E_{1}$ raises from $1.82 \mathrm{kcal} \mathrm{mol}^{-1}$ to $14.5 \mathrm{kcal} \mathrm{mol}^{-1}$ (Fig. 6a). A similar trend is observed when the $\gamma$-proton is added onto the $\beta$-protonated triphosphate (with $\Delta E_{1}$ 

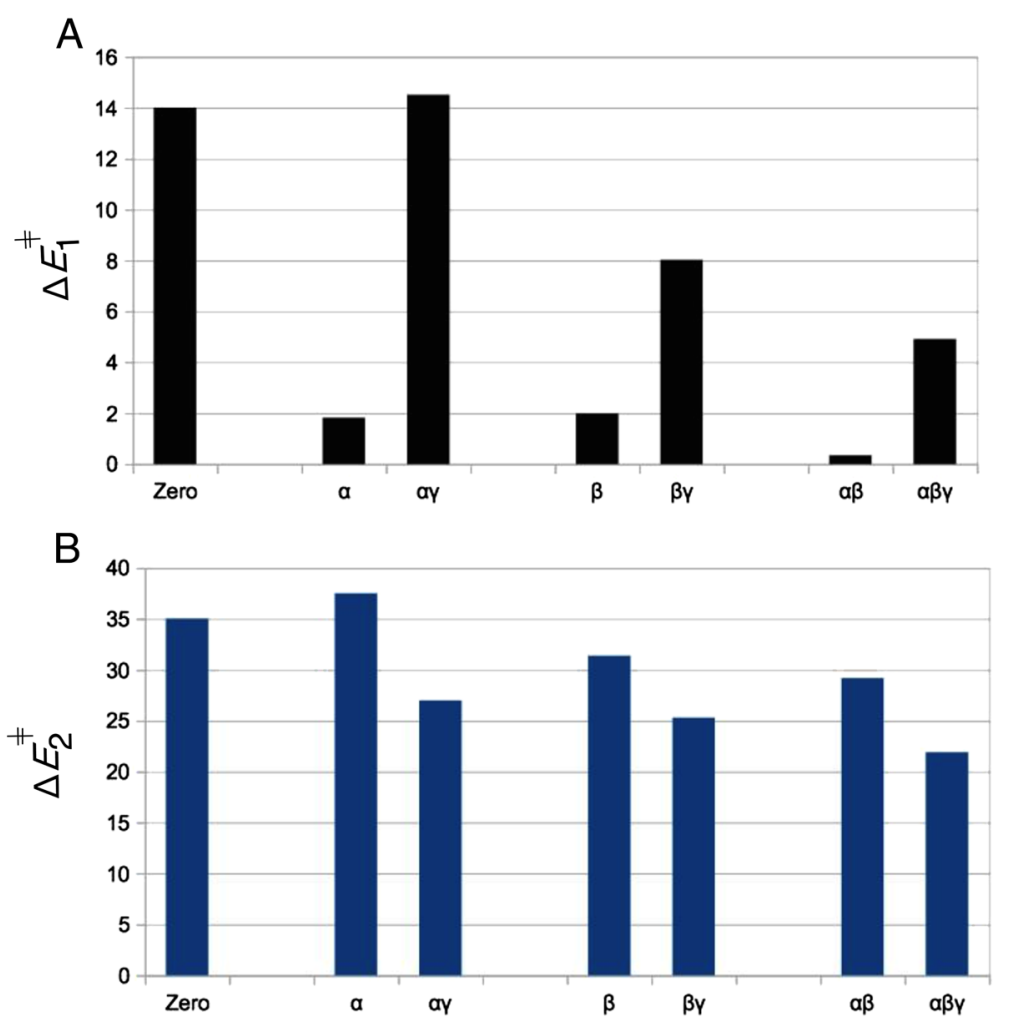

Fig. 6 Effect of protonation on the two steps of the sequential mechanism. Energy barriers a $\Delta E_{1}^{\ddagger}$ for breaking the $P_{Y}-O_{\beta \gamma}$ bond and $\mathbf{b} \Delta E_{2}^{\neq}$for breaking of water $W_{a}$ (as given in Table 2). Greek letters $(\alpha, \beta, \gamma)$ indicate on which phosphate the proton is located (for example ay means ay-protonation). Zero means that there are no protons on the triphosphate $\left(n_{p}=0\right)$

raising from $1.99 \mathrm{kcal} \mathrm{mol}^{-1}$ to $8.02 \mathrm{kcal} \mathrm{mol}^{-1}$ ), or when added to the $\alpha \beta$-protonated

triphosphate $\left(\Delta E_{1}\right.$ increases from $0.34 \mathrm{kcal} \mathrm{mol}^{-1}$ to $4.9 \mathrm{kcal} \mathrm{mol}^{-1}$ ), see Fig. 6a. Again, this disfavoring effect of $\gamma$-protonation on $\mathrm{P}_{\gamma}-\mathrm{O}_{\beta \gamma}$ bond breaking is explained by the charge-shift during $\mathrm{P}_{\gamma}-\mathrm{O}_{\beta \gamma}$ bond cleavage. The positive charge of the $\gamma$-proton hinders the shift of the negative charge from the $\gamma$-phosphate to the $\alpha \beta$-diphosphate (Fig. $2 \mathrm{c} \rightarrow \mathrm{d}$ ), thus disfavoring dissociation and raising $\Delta E_{1}$. This effect is strongest in absence of any protons on $\alpha$ and $\beta$. In that case, a single proton on $\gamma$-position even abolishes the sequential reaction (as mentioned in Results, a stable transition state can not be found).

Conversely, $\gamma$-protonation is necessary to be able to observe a concurrent reaction at all. Indeed, all concurrent paths with protonated triphosphate have a proton on the $\gamma$-phosphate (Table 1). In absence of $\gamma$-proton, these MEPs all revert to the sequential mechanism. For example, there is no concurrent MEP for singly $\alpha$-protonated triphosphate, but a concurrent reaction can be found for the $\alpha \gamma$ protonated case (Table 1 ). The same effect is observed for adding a $\gamma$-proton to $\beta$-protonated triphosphate, or for adding a $\gamma$-proton to the $\alpha \beta$ protonated triphosphate. Thus, adding a $\gamma$-proton alters the potential energy surface in such a way that the concurrent mechanism becomes feasible.

3) $\gamma$-protonation favors the breakup of water $W_{a}$ For the sequential reactions, $\gamma$-protonation lowers the activation barrier $\Delta E_{2}$ of water attack: For example, the $\Delta E_{2}$ of $\alpha$-protonated triphosphate decreases from 37.5 to $27.0 \mathrm{kcal} \mathrm{mol}^{-1}$ in $\alpha \gamma-$ protonated triphosphate, a reduction of $10.5 \mathrm{kcal}$ $\mathrm{mol}^{-1}$ upon addition of the $\gamma$-proton (see Fig. 6b). Similarly, $\Delta E_{2}$ of $\beta$-protonated methyl triphosphate $\left(31.4 \mathrm{kcal} \mathrm{mol}^{-1}\right)$ reduces to $25.3 \mathrm{kcal} \mathrm{mol}^{-1}$ upon addition of the $\gamma$-proton, and addition of the $\gamma^{-}$ proton to $\alpha \beta$-protonated triphosphate reduces the barrier from 29.2 to $21.9 \mathrm{kcal} \mathrm{mol}^{-1}$ (Fig. 6b). The reason for this effect is that $\gamma$-protonation yields a neutral metaphosphate intermediate of the form $\mathrm{HP}_{\gamma} \mathrm{O}_{3}$. It is not negatively charged (unlike the un-protonated $\mathrm{P}_{\gamma} \mathrm{O}_{3}^{-}$), which reduces the electrostatic repulsion between the partial negative charge on oxygen $\mathrm{O}_{a}$ of water $\mathrm{W}_{\mathrm{a}}$ and the $\gamma$ metaphosphate. Therefore, the $\gamma$-protonated metaphosphate is a better target for nucleophilic attack by $\mathrm{W}_{\mathrm{a}}$ (and its accompanying breakup) than the 
un-protonated $\mathrm{PO}_{3}^{-}$. The same effect is at work in the concurrent reactions, where all reactions for triphosphate with a $\gamma$-proton can be seen (in Table 1) to have a lower activation barrier $\Delta E$ than the un-protonated $\left(\mathrm{n}_{\mathrm{P}}=0\right)$ case $\left(\Delta E=44 \mathrm{kcal} \mathrm{mol}^{-1}\right)$. Thus, for both concurrent and sequential mechanisms, protonation in the $\gamma$-position lowers the energy barrier of water breakup and attack.

4) The sequential mechanism yields lower rate-limiting barriers

Even though $\Delta E_{2}$ (the barrier of the second step in sequential pathways) is always higher than the $\Delta E_{1}$ barrier (i.e., $\Delta E_{2}>\Delta E_{1}$, see Table 2), $\Delta E_{2}$ is always lower than the rate-limiting barrier $\Delta E$ of the corresponding (i.e., for a given protonation state) concurrent pathway (compare Tables 1 and $2)$. For example for $\alpha \gamma$-protonation, the sequential $\Delta E_{2} \quad\left(=27.0 \mathrm{kcal} \mathrm{mol}^{-1}\right)$ is $7.5 \mathrm{kcal} \mathrm{mol}^{-1}$ lower than the concurrent $\Delta E \quad\left(=34.5 \mathrm{kcal} \mathrm{mol}^{-1}\right)$. Likewise for the un-protonated case $\left(\mathrm{n}_{\mathrm{P}}=0\right)$, where $\Delta E_{2} \quad(=35 \mathrm{kcal}$ $\left.\mathrm{mol}^{-1}\right)$ is $9 \mathrm{kcal} \mathrm{mol}^{-1}$ less than $\Delta E \quad\left(=44 \mathrm{kcal} \mathrm{mol}^{-1}\right)$. This $\Delta E_{2}<\Delta E$ rule applies also in the other protonation cases, $\beta \gamma$ and $\alpha \beta \gamma$. One explanation is that the metaphosphate molecule $\mathrm{P}_{\gamma} \mathrm{O}_{3}^{-}$(or $\mathrm{HP}_{\gamma} \mathrm{O}_{3}$ if $\gamma$-phosphate was protonated) generated by dissociation step 1 (Fig. 2c) is a much better target for water $\mathrm{W}_{\mathrm{a}}$ than the $-\mathrm{OP}_{\gamma} \mathrm{O}_{3}^{2-}$ (or $-\mathrm{OP}_{\gamma} \mathrm{O}_{3} \mathrm{H}^{-}$) group of un-dissociated triphosphate, for two reasons: a) The metaphosphate is planar, a geometry that allows closer approach of the attacking water $\mathrm{W}_{\mathrm{a}}$ than the tetrahedral $-\mathrm{O}-\mathrm{PO}_{3}$ group. b) The metaphosphate has one less negative charge than the undissociated $-\mathrm{OPO}_{3}$ group (for a given protonation of the $\gamma$-phosphate), thus generating less electrostatic repulsion with the negative partial charge on oxygen $\mathrm{O}_{\mathrm{a}}$ of water $\mathrm{W}_{\mathrm{a}}$. The other reason for having $\Delta E_{2}<\Delta E$ is that in the concurrent mechanism, the energetic cost of the breaking water $\mathrm{W}_{\mathrm{a}}$ and breaking the $\mathrm{P}_{\gamma} \mathrm{O}_{\beta \gamma}$ bond are paid simultaneously in a single transition state, while in the sequential mechanism, these costs are spread over two transition states.

\section{Implications for triphosphate hydrolysis in enzymes Catalytic strategy}

There are clear parallels between the hydrolytic reaction in enzymes and the $\alpha \beta \gamma$-protonation case described above in terms of the resulting sequential mechanism and the respective energy barriers: The lowest barrier of hydrolysis in vacuum is obtained here when all three phosphates $(\alpha, \beta, \gamma)$ of triphosphate are protonated, with a sequential mechanism $\left(\Delta E_{1}=4.9 \mathrm{kcal} \mathrm{mol}^{-1}\right.$ and $\Delta E_{2}$ $=21.9 \mathrm{kcal} \mathrm{mol}^{-1}$ ). Likewise, it has been shown recently for several NTPases (myosin, [7, 21] kinesin, [24] $\mathrm{F}_{1}$ ATPase, [22] RAS-GAP [27, 28] ) that they all have a catalytic mechanism that is sequential, involving the initial formation of a $\mathrm{P}_{\gamma} \mathrm{O}_{3}^{-}$metaphosphate, followed by the attack of the lytic water (which is always placed like $\mathrm{W}_{\mathrm{a}}$ in Fig. 2a and b). This similarity is not due to protonation of the phosphates in the enzyme (computational studies indicate that the triphosphate is fully deprotonated when bound in the catalytic pocket), [21] but arises because interaction of each phosphate group with its positively charged protein environment promotes similar charge-shifts within the triphosphate as those described above for the protonation in vacuum. For example in myosin, the six hydrogen bonds of the P-loop are all made to the $\alpha \beta$-phosphates (see Fig. 2a), thus pulling negative charge away from the $\mathrm{P}_{\beta}-\mathrm{O}_{\beta \gamma}$ bond. This is likely to have a similar lowering effect on the $\Delta E_{1}$ barrier as the charge shift induced by the protonation on the $\alpha$ and/or $\beta$ phosphates (which lowers $\Delta E_{1}$ by $12-14 \mathrm{kcal}$ $\mathrm{mol}^{-1}$, see Fig. 6a). The three $\mathrm{H}$-bonds donated to the $\gamma$ phosphate by the Ser181 side chain and the backbone of Ser236 and Gly457 (Fig. 2a) make the $\gamma$-phosphorus become a better target for nucleophilic attack by water $\mathrm{W}_{\mathrm{a}}$, probably contributing to the lowering of $\Delta E_{2}$ in the enzyme in a similar way as protonation of the $\gamma$ phosphates (which lowers $\Delta E_{2}$ by $6-10 \mathrm{kcal} \mathrm{mol}^{-1}$, see Fig. 6b). A crude estimate of the amount of positive charge placed in direct contact with the triphosphate in myosin can be made: the nine $\mathrm{H}$-bonds and Lys $185^{+}$ amount to approximately +3.25 charges (counting $\sim 0.25$ charge per $\mathrm{H}$-bond, which is the typical partial atomic charge on a proton of backbone $\mathrm{NH}$ groups in classical force-fields) [29]. Of course this number is not a true net charge (it neglects the counter-charge of each $\mathrm{H}$ bond dipole), but it is close to the +3 charge of three protons distributed onto the $\alpha-, \beta$ - and $\gamma$-protonated triphosphate. Thus it is not surprising that the $\Delta E_{1}$ barrier obtained for myosin $\left(8.7 \mathrm{kcal} \mathrm{mol}^{-1}\right)$ is nearly as low as the $\Delta E_{1}$ obtained with triply protonated triphosphate in vacuum $\left(4.9 \mathrm{kcal} \mathrm{mol}^{-1}\right)$.

In the present vacuum simulations, the proton abstracted from $\mathrm{W}_{\mathrm{a}}$ was transferred to the $\gamma$-phosphate (in both the concurrent and sequential reactions). Thus the $\gamma$-phosphate serves as both the proton acceptor and as the general base that activates water $\mathrm{W}_{\mathrm{a}}$. In the enzymes, the final acceptor of the proton is also the dissociated $\gamma$ phosphate, but the NTPases utilize an external catalytic base (e.g., Glu459 in myosin, see Fig. 2a) to activate water $\mathrm{W}_{\mathrm{a}}$. This external base serves to polarize water $\mathrm{W}_{\mathrm{a}}$, either directly (in RAS-GAP [27]) or via an intercalating helping water molecule $\left(\mathrm{W}_{\mathrm{h}}\right.$ in Fig. $\left.2 \mathrm{a}\right)$. This allows the enzymes to further lower the barrier for lysis of water $\mathrm{W}_{\mathrm{a}}$, and thus facilitate water attack onto the dissociated metaphosphate. In this way, the barrier for step 2 of the sequential reaction $\left(\Delta E_{2}\right)$ can be lowered even more than can be achieved by only having partial 
positive charges interacting with the $\gamma$-phosphate group (described above).

During step 2 of the present sequential pathways in vacuum, the proton abstracted from water $\mathrm{W}_{\mathrm{a}}$ is directly transferred onto the oxygen of the $\gamma$-phosphate. The corresponding transition state contains a 4-membered ring $\left(\mathrm{P}_{\gamma}-\mathrm{O}_{\gamma}-\mathrm{H}_{\mathrm{a}}-\mathrm{O}_{\mathrm{a}}-\mathrm{P}_{\gamma}\right)$, which induces some strain. In the enzymes, this transfer occurs via either a helping water $\left(\mathrm{W}_{\mathrm{h}}\right)$ and/or the alcohol group of a nearby Serine side chain (for example Ser181 in myosin, see Fig. 2a) [21]. The resulting 6- or 8-membered ring in the transition state allows for less strain, thereby further lowering the barrier $\Delta E_{2}$. Together with the activation from an external base, this explains how the enzymes manage to bring $\Delta E_{2}$ down to values as low as $10-17 \mathrm{kcal} \mathrm{mol}^{-1}$, $[21,22,30-32]$ while in vacuum the lowest value that could be achieved here for $\Delta E_{2}$ is $21.9 \mathrm{kcal} \mathrm{mol}^{-1}$ (for $\alpha \beta \gamma$ triple protonation, Table 2).

In all combined quantum mechanical/classical (QM/ MM) simulations of ATP hydrolysis in myosin during which a proton had first transferred to the $\gamma$-phosphate, the mechanism has always been found to be concurrent, never sequential [5,33-37]. This is consistent with the results obtained here: Whenever the $\gamma$-phosphate is protonated, the $\mathrm{P}_{\gamma}-\mathrm{O}_{\beta \gamma}$ bond is strengthened, preventing a sequential mechanism with prior breaking of the $\mathrm{P}_{\gamma}-\mathrm{O}_{\beta \gamma}$ bond. Conversely, in all those calculations in which the $\gamma$-phosphate was not protonated, the mechanism has been observed to be sequential [7, 21, 38]. Similarly, in $\mathrm{QM} / \mathrm{MM}$ simulations of the phosphoryl transfer reaction in bovine protein tyrosine phosphatase (BPTP), [39] it was shown that the phosphoryl transfer occurs via a sequential mechanism with a $9 \mathrm{kcal} \mathrm{mol}^{-1}$ barrier when the leaving phosphate group is unprotonated $[39,40]$. In contrast, when the leaving phosphate group was protonated, phosphoryl transfer was seen to occur via a concurrent mechanism with a barrier of $22 \mathrm{kcal} \mathrm{mol}^{-1}$ [39]. This can be explained in the same terms as for the effect of $\gamma$-protonation on triphosphate hydrolysis: Protonation of the terminal phosphate strengthens the $\mathrm{P}-\mathrm{O}$ bond, and the $\mathrm{P}-\mathrm{O}$ bond cleavage become concurrent, thus resulting in a higher barrier.

\section{Conclusions}

A clear set of rules for the effects of $\alpha$-, $\beta$ - or $\gamma$ - protonation on triphosphate hydrolysis in vacuum can be identified. They are: 1) Protonation of the $\alpha$ - or $\beta$-phosphate promotes $\mathrm{P}_{\gamma}-\mathrm{O}_{\beta \gamma}$ bond cleavage, thus favoring a sequential reaction. 2) Protonation on $\gamma$ favors a concurrent reaction, thus disfavoring the sequential pathway. 3) $\gamma$-protonation facilitates the attack of water onto the $\gamma$-phosphorus. These effects are somewhat additive, so that simultaneous protonation on the $\gamma$ - and $\alpha$ - (or $\gamma$ - and $\beta$-) positions can result in both concurrent and sequential reactions. These rules can be explained in terms of the charge distribution on the phosphates: i) $\alpha$ - and/or $\beta$-protonation pulls electrons towards the $\alpha, \beta$-diphosphate moiety, favoring the charge distribution of the dissociated state (Fig. 2d). ii) $\gamma$-protonation has the opposite effect, pulling electrons towards the $\gamma$ phosphate, favoring the un-dissociated charge distribution (Fig. 2c), thereby making dissociation less favorable. iii) $\gamma$ protonation reduces the negative charge of the $\gamma$ phosphate, which thus becomes a better target for the nucleophilic attack by water $\mathrm{W}_{\mathrm{a}}$.

Breaking-up a water molecule is very difficult, and is the rate-limiting step in all pathways. Therefore, the sequential pathways tend to have a lower rate-limiting barrier than the concurrent reactions. One reason is that the energetic cost of breaking the $\mathrm{P}_{\gamma}-\mathrm{O}_{\beta \gamma}$ bond $\left(\Delta E_{1}\right)$ has already been paid in the previous step. The other reason is that the dissociated $\gamma$-phosphate (Fig. 2d) is planar and less negatively charged than the undissociated $\gamma$-phosphate (Fig. 2c), making the former a better target for the nucleophilic attack by water $\mathrm{W}_{\mathrm{a}}$. For this reason, the lowest energy barrier of hydrolysis is obtained for the $\alpha, \beta, \gamma$-protonated case, which combines all effects.

The present calculations are consistent with experimental studies: Uncatalyzed phosphoryl transfer reaction from ATP, GTP and pyrophosphate are suggestive that the beta-gamma-bridging oxygen atom undergoes significant charge-increase (of -0.55 e) [41]. Charge shift was also observed in the RAS catalyzed hydrolysis of GTP in GAP using time-resolved Fourier transform infrared difference spectroscopy [42]. In NTPases, the charge shifts are induced by placing many positive partial charges in direct contact with each of the three phosphate groups. Additionally, the NTPases further lower the rate-limiting barrier of water lysis by placing a residue (such as Glu459 in myosin, Fig. 2a) nearby that acts as a better general base for water activation than the $\gamma$-phosphate. The present study helps to better understand the respective role of the many $\mathrm{H}$-bond donors and positive charges in the active site of NTPases. Depending on its placement, each of these groups contributes differently to the catalytic mechanism, according to the set of rules listed above. It is known that ATP- $\gamma$-S is far more stable than ATP, [43] and is not easily hydrolyzed by enzymes $[44,45]$. An interesting computational study would be to compare the catalysis of ATP- $\gamma-\mathrm{S}$ with that of ATP.

\section{Methods}

In NTPase enzymes, the triphosphate moiety of NTP is complexed with a hexa-coordinated $\mathrm{Mg}^{2+}$ cation, therefore $\mathrm{Mg}^{2+}\left(\mathrm{H}_{2} \mathrm{O}\right)_{4}$-coordinated methyl triphosphate (shown in Fig. 1) was used here as substrate. Harmonic 
distance constraints between the oxygen and hydrogen atoms of magnesium coordinated water molecules were used to prevent undesired proton transfer from these waters to the triphosphate. In all cases studied here, water $\mathrm{W}_{\mathrm{a}}$ is taken to transfer one of its protons to the nearest phosphate oxygen, namely of the $\gamma$-phosphate. This proton transfer mechanism is referred to as direct proton transfer $[7,46]$. Reactant and product structures (see Fig. 1) were energy-optimized for each protonation case using the AM1/d semi-empirical method, [47] with phosphorus parameters modified from those of York et. al. [48] and magnesium parameters designed to be combinable with phosphorus, as previously described [20]. The minimum energy paths (MEPs) and all first order saddle point between the reactant and product structures were computed with the Conjugate Peak Refinement (CPR) method, [49] as implemented in the Trek module of CHARMM [29].

CPR finds the MEP by starting from an initial guess of the path, here the linear interpolation between the Cartesian coordinates of reactant and product. The path is treated as a chain of conformers, and this chain is gradually relaxed (by a controlled energy optimization of all the chain conformers) into a valley of the potential energy surface. By applying appropriate external constraints on the distance between the $\mathrm{P}_{\gamma}$ and the attacking $\left(\mathrm{O}_{\mathrm{a}}\right)$ and leaving $\left(\mathrm{O}_{\beta \gamma}\right)$ oxygen atoms, the potential energy surface was initially shaped to make sure that the desired (either concurrent or a sequential) reaction valley is present for each case of protonation. The CPR search for a MEP was started with this "shaped" potential. Once the path-chain follows the desired valley (for example sequential), the shaping constraints are removed and the path optimization is continued with CPR. This procedure ensures that, when a valley for a given reaction type (for example concurrent) is present on the native (i.e. unshaped) energy surface, then this valley is found. Conversely, if the desired reaction type has no valley on the native potential, then after the shaping constraints are removed, CPR transforms the pathchain until it follows the actual (sequential in this example) reaction valley.

Given the large number of structures that are present along each MEP and that have to be energy-optimized (i.e., not only the transition states were optimized), it was helpful to use a semi-empirical QM method rather than (much slower) DFT methods. Starting from AM1/d parameters developed for phosphate $/ \mathrm{Mg}^{2+}$ complexes, [20] we further optimized the parameters of phosphorus for the computation of transition states of phosphate hydrolysis (listed in Table S2) [50]. A comparison of the resulting energies for the hydrolysis reaction of dimethyl phosphate (complexed with $\mathrm{Mg}^{2+}$ and five water molecules) showed that the AM1/d method can reproduce the relative energy barriers obtained with DFT (B3LYP/ $6-31++G(d, p))$, both for sequential [50] as well as for concurrent $[50,51]$ mechanisms. Here, we also compared the reactant and the saddle point structures for the concurrent mechanism with fully deprotonated methyl-triphosphate obtained with the B3LYP/6-31+ $\mathrm{G}^{* *}$ method to those obtained with these optimized AM1/d parameters. They are shown in Additional file 1: Figure S1A and S1B and the corresponding activation barriers are given in Additional file 1: Table S1. The same comparison was done for the sequential mechanism with $\alpha$ protonated triphosphate (Additional file 1: Figure S1C and S1D, Table S1). The resulting structures and the energy barriers are qualitatively similar, with an error for the activation barrier of less than $10 \%$, which shows that the present AM1/d method/parameters are adequate to study the effects of protonation on the barriers of triphosphate hydrolysis. Note that we found that the relative energy of the $\mathrm{ADP} / \mathrm{P}_{\mathrm{i}}$ products (i.e., after the crossing of all the barriers, at $\lambda=1$ in Fig. 3 ) is not reliable with the AM1/d method, which tends to overstabilize the products compared to the reactant energy. It is possible that results of the completely or partly unprotonated triphosphate hydrolysis may alter when treated in solution. This is because these negatively charged triphosphate species would get more stable towards $\mathrm{P}-\mathrm{O}$ bond cleavage in solutions.

\section{Additional files}

Additional file 1: Supporting Information. Figure S1. Comparison of structures optimized with B3LYP/6-31+G $\mathrm{G}^{* *}$ (colored) and AM1/d (gray). Table S1. Comparison of the AM1/d and B3LYP/6-31+G** methods. Table S2. Modified Phosphorus parameters used in the AM1/d calculations. (DOC $3 \mathrm{mb}$ )

Additional file 2: Movie C1. Concurrent minimum energy path (MEP) for hydrolysis of unprotonated triphosphate $(\mathrm{nP}=0)$ ). (MPG $1 \mathrm{mb}$ )

Additional file 3: Movie C2. Concurrent MEP for hydrolysis of triphosphate singly protonated $(\mathrm{nP}=1)$ on the $\gamma$ phosphate. (MPG $595 \mathrm{~kb}$ ) Additional file 4: Movie C3. Concurrent MEP for hydrolysis of triphosphate doubly protonated $(\mathrm{nP}=2)$ on a and $\mathrm{y}$ phosphate. (MPG $787 \mathrm{~kb})$

Additional file 5: Movie C4. Concurrent MEP for hydrolysis of triphosphate doubly protonated $(\mathrm{nP}=2)$ on $\beta$ and $\gamma$ phosphate. (MPG $843 \mathrm{~kb}$ )

Additional file 6: Movie C5. Concurrent MEP for hydrolysis of triphosphate triply protonated ( $\mathrm{nP}=3$ ) on $\mathrm{a}, \beta$ and $\gamma$ phosphate. (MPG $1 \mathrm{mb}$ )

Additional file 7: Movie S1. Sequential MEP for hydrolysis of un-protonated triphosphate $(\mathrm{nP}=0)$ ). (MPG $876 \mathrm{~kb})$

Additional file 8: Movie S2. Sequential MEP for hydrolysis of triphosphate singly protonated ( $\mathrm{nP}=1$ ) on the a phosphate. (MPG $550 \mathrm{~kb}$ )

Additional file 9: Movie S3. Sequential MEP for hydrolysis of triphosphate singly protonated $(\mathrm{nP}=1)$ on the $\beta$ phosphate. (MPG $793 \mathrm{~kb}$ )

Additional file 10: Movie S4. Sequential MEP for hydrolysis of triphosphate doubly protonated $(\mathrm{nP}=2$ ) on the $\mathrm{a}, \beta$ phosphates. (MPG $793 \mathrm{~kb}$ )

Additional file 11: Movie S5. Sequential MEP for hydrolysis of triphosphate doubly protonated $(\mathrm{nP}=2)$ on the $a, y$ phosphates. (MPG $777 \mathrm{~kb}$ )

Additional file 12: Movie S6. Sequential MEP for hydrolysis of triphosphate doubly protonated ( $\mathrm{nP}=2$ ) on the $\beta, \gamma$ phosphates. (MPG $1 \mathrm{mb}$ )

Additional file 13: Movie S7. Sequential MEP for hydrolysis of triphosphate triply protonated $(\mathrm{nP}=3$ ) on the $a, \beta, \gamma$ phosphates. (MPG $1 \mathrm{mb}$ ) 


\section{Abbreviations}

ATP, adenosine triphopshate; MEP, minimum energy path; NTP, nucleoside triphsophate

\section{Funding}

Financial support by Deutsche Forschungsgemeinschaft (DFG) through Sonderforschungbericht-623 is gratefully acknowledged. Authors declare no conflict of interest.

\section{Availability of data and materials}

The datasets supporting the conclusions of this article are included within the article and its additional files.

\section{Authors' contributions}

SF designed the simulation setup, and contributed in editing the manuscript. FAK performed the calculations, and contributed in writing the manuscript. All authors read and approved the final manuscript.

\section{Competing interests}

The authors declare that they have no competing interests.

\section{Ethics approval and consent to participate}

Not applicable.

\section{Author details \\ ${ }^{1}$ Computational Biochemistry, Interdisciplinary Center for Scientific Islamabad, Pakistan. \\ Received: 29 February 2016 Accepted: 14 June 2016 \\ Published online: 29 June 2016} Computing (IWR), Heidelberg University, Im Neuenheimer Feld 205, D-69120 Heidelberg, Germany. ${ }^{2}$ Research Center for Modeling and Simulation (RCMS), National University of Sciences and Technology (NUST), Sector H-12, 44000

\section{References}

1. Glaves R, Mathias G, Marx D. J Am Chem Soc. 2012;134:6995-7000.

2. Kamerlin SCL, Sharma PK, Prasad RB, Warshel A. Q Rev Biophys. 2013:46:1-132.

3. Trentham DR, Eccleston JF, Bagshaw CR. Q Rev Biophys. 1976;9:217-81.

4. Miller DL, Westheimer FH. J Am Chem Soc. 1966:88:1507-11.

5. Ramirez F, Marecek JF, Szamosi J. J Org Chem. 1980;45:4748-52.

6. Glennon TM, Villa J, Warshel A. Biochemistry. 2000;39:9641-51.

7. Kiani FA, Fischer S. Curr Opin Struct Biol. 2015;31:115-23.

8. Hu C-H, Brinck T. J Phys Chem A. 1999;103:5379-86.

9. Grigorenko BL, Rogov AV, Nemukhin AV. J Phys Chem B. 2006;110:4407-12.

10. Kiani FA, Fischer S. In: Hofmann P, Gade LH, editors. Molecular Catalysts: Structure and Functional Design. Weinheim: Wiley-VCH; 2014. p. 359-76.

11. Li XD, Rhodes TE, Ikebe R, Kambara T, White HD, Ikebe M. J Biol Chem. 1998; 273:27404-11.

12. Hanson PI, Whiteheart SW. Nat Rev Mol Cell Biol. 2005;6:519-29.

13. Senior AE, al-Shawi MK. J Biol Chem. 1992;267:21471-8.

14. Shimada T, Sasaki N, Ohkura R, Sutoh K. Biochemistry. 1997;36:14037-43.

15. Scheffzek K, Ahmadian MR, Kabsch W, Wiesmuller L, Lautwein A, Schmitz F, Wittinghofer A. Science. 1997;277:333-8.

16. Ahmadian MR, Stege P, Scheffzek K, Wittinghofer A. Nat Struct Biol. 1997;4:686-9.

17. Komoriya Y, Ariga T, lino R, Imamura H, Okuno D, Noji H. J Biol Chem. 2012; 287:15134-42.

18. Branduardi D, Marinelli F, Faraldo-Gomez JD. J Comput Chem. 2015;DOI:10. 1002/jcc.23991

19. Alberty RA. J Biol Chem. 1968:243:1337-43.

20. Imhof P, Noé F, Fischer S, Smith JC. J Chem Theory Comput. 2006;2:1050-6.

21. Kiani FA, Fischer S. Proc Natl Acad Sci U S A. 2014;111:E2947-56.

22. Hayashi S, Ueno H, Shaikh AR, Umemura M, Kamiya M, Ito Y, Ikeguchi M, Komoriya Y, lino R, Noji H. J Am Chem Soc. 2012;134:8447-54.

23. Grigorenko BL, Rogov AV, Topol IA, Burt SK, Martinez HM, Nemukhin AV. Proc Natl Acad Sci U S A. 2007;104:7057-61.

24. McGrath MJ, Kuo I-F W, Hayashi S, Takada S. J Am Chem Soc. 2013;135: 8908-19.

25. Kiani FA, Fischer S.J Biol Chem. 2013:288:35569-80.

26. Kiani FA, Fischer S. Phys Chem Chem Phys 2016; DOI: 10.1039/C6CP01364C

27. Grigorenko BL, Nemukhin AV, Topol IA, Cachau RE, Burt SK. Proteins. 2005: 60:495-503.
28. Grigorenko BL, Nemukhin AV, Shadrina MS, Topol IA, Burt SK. Proteins. 2007; 66:456-66.

29. Brooks BR, Brooks III CL, Mackerell Jr AD, Nilsson L, Petrella RJ, Roux B, Won Y, Archontis G, Bartels C, Boresch S, Caflisch A, Caves L, Cui Q, Dinner AR, Feig M, Fischer S, Gao J, Hodoscek M, Im W, Kuczera K, Lazaridis T, Ma J, Ovchinnikov V, Paci E, Pastor RW, Post CB, Pu JZ, Schaefer M, Tidor B, Venable RM, Woodcock HL, Wu X, Yang W, York DM, Karplus MJ. J Comput Chem. 2009;30:1545-614.

30. Málnási-Csizmadia A, Pearson DS, Kovács M, Woolley RJ, Geeves MA, Bagshaw CR. Biochemistry. 2001:40:12727-37.

31. Cochran JC, Gilbert SP. Biochemistry. 2005;44:16633-48.

32. Cochran JC, Krzysiak TC, Gilbert SP. Biochemistry. 2006:45:12334-44.

33. Yang Y, Cui Q. J Phys Chem A. 2009;113:12439-46.

34. Okimoto N, Yamanaka K, Ueno J, Hata M, Hoshino T, Tsuda M. Biophys J. 2001;81:2786-94.

35. Li G, Cui Q. J Phys Chem B. 2004;108:3342-57.

36. Schwarzl S, Smith JC, Fischer S. Biochemistry. 2006;45:5830-47.

37. Yang Y, Yu H, Cui Q. J Mol Biol. 2008;381:1407-20.

38. Grigorenko BL, Kaliman IA, Nemukhin AV. J Mol Graphics Modell. 2011;31:1-4.

39. Asthagiri D, Dillet V, Liu T, Noodleman L, Etten RLV, Bashford D. J Am Chem Soc. 2002:124:10225-35.

40. Cleland WW, Hengge AC. Chem Rev. 2006;106:3252-78.

41. Admiraal SJ, Herschlag D. Chem Biol. 1995;2:729-39.

42. Allin C, Ahmadian MR, Wittinghoffer A, Gerwert K. Proc Natl Acad Sci. 2001; 98:7754-9.

43. Eckstein F. Angew Chem Int Ed Engl. 1983;22:423-39.

44. Eckstein F. Ann Rev Biochem. 1985:54:367-402.

45. Zhang Y-L, Hollfelder F, Gordon SJ, Chen L, Keng Y-F, Wu L, Herschlag D, Zhang Z-Y. Biochemistry. 1999;38:12111-23.

46. Wang C, Huang W, Liao J-L. J Phys Chem. 2015;119:3720-6.

47. Dewar MJS, Zoebisch EG, Healy EF, Stewart JJP. J Am Chem Soc. 1985;107:3902-9.

48. Nam K, Cui Q, Gao J, York DM. J Chem Theory Comput. 2007;3:486-504.

49. Fischer S, Karplus M. Chem Phys Lett. 1992;194:252-61.

50. Imhof P, Fischer S, Smith JC. Biochemistry. 2009;48:9061-75.

51. Marcos E, Anglada JM, Crehuet R. Phys Chem Chem Phys. 2008;10:2442-50.

\section{Submit your next manuscript to BioMed Central and we will help you at every step:}

- We accept pre-submission inquiries

- Our selector tool helps you to find the most relevant journal

- We provide round the clock customer support

- Convenient online submission

- Thorough peer review

- Inclusion in PubMed and all major indexing services

- Maximum visibility for your research

Submit your manuscript at www.biomedcentral.com/submit
Biomed Central 